\title{
Emission rates of substances from low-volatile-organic-compound paints
}

\author{
N. Suzuki ${ }^{1} \cdot$ H. Nakaoka ${ }^{1} \cdot$ M. Hanazato ${ }^{1} \cdot$ Y. Nakayama $^{1} \cdot$ K. Takaya ${ }^{1} \cdot$ C. Mori $^{1,2,3}$
}

Received: 4 June 2018 / Revised: 22 October 2018 / Accepted: 24 October 2018 / Published online: 30 October 2018

(c) The Author(s) 2018

\begin{abstract}
Globally, sick building syndrome remains a considerable social issue. It is primarily caused by the emission of volatile organic compounds (VOCs) from construction materials. Among these, paints and sealers are used over wide swaths of are a and their use causes chemical substances to be released in a room. To prevent sick building syndrome, it is necessary to clarify the cause of air quality changes due to the different types of paints and sealers available. Recently, low-VOC paints (containing 0.3-1.0\% VOCs) have been used widely; however, the effects of reducing VOC levels have not yet been fully quantified. This study aims to clarify the chemical compositions by conducting an emission rate test of these low-VOC paints and sealers. We prepared six specimens and used them for chamber testing. Three types of paint with and without a sealer were tested. The minimum and maximum total volatile organic compound (TVOC) concentration was 96 and $4750 \mu \mathrm{gm}^{-2} \mathrm{~h}^{-1}$, respectively. Differences in the VOC content of the paints and sealers could be confirmed. The main TVOC was Texanol ${ }^{\mathrm{TM}}$ and glycerol ethers. The results demonstrate that using paints containing less than $0.3 \%$ VOCs can decrease the VOC emission rate considerably compared to paints classified as less than $1 \%$ VOCs. Moreover, because different kinds of sealers affected the results, it is possible to decrease VOC emission rate using a variety of sealers.
\end{abstract}

Keywords Indoor air quality $\cdot$ Low-volatile-organic-compound paints $\cdot$ Sealer $\cdot$ Small chamber test

\section{Introduction}

The enactment of interior concentration guideline values by the Ministry of Health, Labor, and Welfare of Japan (MHLW) and the revision of the Building Standard Law have been accompanied by the declining reports of sick building syndrome (SBS); nevertheless, the SBS problem remains unresolved. The symptoms of SBS vary greatly between individuals. Additionally, the concentration of every chemical substance that causes SBS symptoms and the sensitivity to each chemical varies between individuals

Editorial responsibility: U.W. Tang.

C. Mori

suzu-nori@chiba-u.jp

1 Center for Preventive Medical Sciences, Chiba University, 6-2-1 Kashiwanoha, Kashiwa, Chiba 277-0882, Japan

2 Center for Preventive Medical Sciences, Chiba University, 1-8-1 Inohana, Chuo-ku, Chiba-shi, Japan

3 Graduate School of Medicine, Chiba University, Chiba 260-8672, Japan
(Norbäck et al. 1990a, b; Nordström et al. 1995). For these reasons, specifying the causes of SBS is extremely difficult and it is still treated as a social problem.

The major cause of SBS is suspected to be volatile organic compounds (VOCs) emitted by building materials (Mori and Todaka 2011; Heinrich 2011; Herberth et al. 2009; Azuma et al. 2016; Brinke et al. 1998; Hodgson 2002; Molhave 2003; Schneider et al. 2003; Kim et al. 2012; Alevantis 1996; Zhang and Ying 2003; Fang et al. 1999; Deng and Kim 2004). Technological advances in recent years have led to an increase in highly airtight and highly insulated homes and have significantly reduced home energy consumption for heating and cooling. Meanwhile, increasing the airtightness and building insulation levels have caused the chemical substances emitted from building materials and interior finishing to remain in homes for a longer duration, deteriorating interior air quality. It is hypothesized that the large quantities of chemical substances are emitted inside rooms from paints and sealers as they are liberally applied over large surface areas. Although paint is a familiar building material that is handled casually, correlations between air quality and paint types used should be clarified to prevent SBS. The Japanese 
Ministry of Environment requests the industry to reduce the release of VOCs into the environment and recommends the use of low-VOC paints as a VOC reduction strategy (2007). However, very little investigation has been performed in Japan concerning the emissions of VOCs from so-called low-VOC paints. Additionally, Park et al. (2017) examined the effect of low-VOC, water-based paint on allergic diseases of schoolchildren in Korea. They concluded that the paint used in their study might not be a major aggravating factor for the allergic diseases in schoolchildren. It is necessary to investigate the relationship between the contents indicated and emission rates also of low-VOC paints and their adverse effects on public health.

The Japan Paint Manufacturers Association (JPMS) has proposed that the water-based paints should be classified from $\mathrm{W} 1$ to $\mathrm{W} 3$ according to their VOC and aromatic hydrocarbon-type solvent contents (Table 1). Using W1 class paints (defined to have VOC contents less than 1\%) is recommended for reducing the VOC concentrations in rooms. In recent years, low-VOC water-based paints with VOC contents lower than $0.2 \%$ or $0.3 \%$ have become available; however, even among W1 class paints, large differences in VOC content are seen. This study aims to clarify the characteristics of chemical substances emitted by W1 class low-VOC paints and sealers by conducting emission rate tests and investigate whether they contain chemical substances which may have adverse effects on human health. Sealers are always used in combination with paints to improve paint performance (Boxall et al. 1992). Kobayashi et al. (2010) have pointed out that sealers also emit Texanol $^{\mathrm{TM}}$, which could be a cause of SBS. Hence, in addition to paints, we also performed comparative texting with and without different types of sealers. The experiments were conducted in November 2015 at Chiba University. Precise analyses were conducted by the Tokyo Kenbikyouin Foundation.

\section{Materials and methods}

\section{Test material}

We prepared six specimens and used them for chamber testing. All paints and sealers were water-based synthetic resin emulsion. Three kinds of paint, i.e., Paint A (PA), Paint B (PB), and Paint $\mathrm{C}(\mathrm{PC})$, that conform with class 1 composite emulsion paints categorized as W1 (VOC content lower than $1 \%$ ), and three types of sealers, i.e., Sealer A (SA), Sealer B (SB), and Sealer C (SC), were tested in assorted combinations. Table 2 shows the combinations of sealers and paints. Under usual application conditions, paints and sealers made by the same manufacturer are typically used together if combined; therefore, in this study, we also used combinations of paints and sealers from the same manufacturer.
Table 1 Classification of paints based on the VOC content

Table 2 Study samples

\begin{tabular}{lllll}
\hline Classification & VOC content (\%) & $\begin{array}{l}\text { Aromatic hydrocarbons } \\
\text { solvent content }(\%)\end{array}$ & Interior & Exterior \\
\hline W1 & Less than 1 & Less than 0.1 & $\bigcirc$ & $\bigcirc$ \\
W2 & 2 or more but less than 5 & Less than 1 & 0 & $\bigcirc$ \\
W3 & More than 5 & Less than 1 & $\Delta$ & $\bigcirc$ \\
\hline
\end{tabular}

\begin{tabular}{|c|c|c|c|c|c|c|c|c|}
\hline Test body & $\begin{array}{l}\text { I } \\
\text { PA }\end{array}$ & $\begin{array}{l}\text { II } \\
\mathrm{PA}+\mathrm{SA}\end{array}$ & $\begin{array}{l}\text { III } \\
\text { PB }\end{array}$ & $\begin{array}{l}\text { IV } \\
\mathrm{PB}+\mathrm{SB}\end{array}$ & $\begin{array}{l}\text { V } \\
\text { PC }\end{array}$ & $\begin{array}{l}\mathrm{VI} \\
\mathrm{PC}+\mathrm{SC}\end{array}$ & Types of paint & VOC content \\
\hline Paint A & $\bigcirc$ & O & & & & & $\begin{array}{l}\text { Synthetic resin } \\
\text { Emulsion paint }\end{array}$ & Less than $0.2 \%$ \\
\hline Paint B & & & O & $\bigcirc$ & & & $\begin{array}{l}\text { Synthetic resin } \\
\text { Emulsion paint }\end{array}$ & Less than $0.3 \%$ \\
\hline Paint C & & & & & O & O & $\begin{array}{l}\text { Synthetic resin } \\
\text { Emulsion paint }\end{array}$ & Less than $1 \%$ \\
\hline Sealer A & & O & & & & & $\begin{array}{l}\text { Synthetic resin } \\
\text { Emulsion sealer }\end{array}$ & - \\
\hline Sealer B & & & & $\bigcirc$ & & & $\begin{array}{l}\text { Synthetic resin } \\
\text { Emulsion sealer }\end{array}$ & - \\
\hline Sealer C & & & & & & 0 & $\begin{array}{l}\text { Synthetic resin } \\
\text { Emulsion sealer }\end{array}$ & - \\
\hline
\end{tabular}




\section{Emission rate test}

The emission rate test was conducted in a $20-\mathrm{L}$ chamber in accordance with the JIS A 1901 small chamber method (JSA. JIS A 1901, based on ISO 16000-9). The chamber and seal boxes were washed with water and baked in an oven at $260{ }^{\circ} \mathrm{C}$ before they were set up to eliminate any pollutants from the chamber itself. All test conditions were adjusted such that the test temperature was $28^{\circ} \mathrm{C}$, relative humidity was $50 \%$, ventilation frequency was 0.5 times $\mathrm{h}^{-1}$, and the test loading rate was $2.25 \mathrm{~m}^{2} \mathrm{~m}^{-3}$. The emission rates for 62 VOCs and 15 aldehydes were measured. The chemical substances measured are presented in Table 3 . The paints were applied to one side of $165 \times 165 \mathrm{~mm}^{2}$ glass plates $(2$ plates) such that the coverage would be $150 \times 150 \mathrm{~mm}^{2}(2$ plates) with a total painted area of $0.045 \mathrm{~m}^{2}\left(0.0225 \mathrm{~m}^{2}\right.$, 2 plates). The painted plates were dried for 1 day at room temperature $\left(23-28{ }^{\circ} \mathrm{C}\right)$. After the paints had set, the painted glass plates fixed in a sealed box that was then placed inside the small chamber.

Measurements were taken on the 7th day after the plates were confined in the small chamber. Precise analyses were conducted by the Tokyo Kenbikyou-in Foundation. Figure 1 show views of the small chamber test. Formaldehyde and acetaldehyde were measured using high-performance liquid chromatography (two LC-20AD liquid pumps and SIL-20AC auto-sampler from Shimadzu). The separation column used was the Ascentis RP-Amide $\left(150 \times 4.6 \mathrm{~mm}^{2}\right.$;
Table 3 VOCs and aldehydes analyzed in this study
62 VOCs and aldehydes analyzed by GC/MS

\begin{tabular}{|c|c|c|}
\hline 2-Propanol & 2-Butoxyethanol & Formaldehyde \\
\hline Pentane & Nonane & Acetaldehyde \\
\hline Ethyl acetate & Tricyclene & Acetone \\
\hline Dichloromethane & $\alpha$-Pinene & 2-Furanacrolein \\
\hline 1-Propanol & 3-Ethyltoluene & Propionaldehyde \\
\hline Ethyl acetate & Camphene & 2-Butanone \\
\hline Hexane & 4-Ethyltoluene & Butanal \\
\hline Chloroform & 1,3,5-Trimethylbenzene & Cyclohexanone \\
\hline 1,2-Dichloroethane & 2-Ethyltoluene & Benzaldehyde \\
\hline 2,4-Dimethylpentane & $\beta$-Pinene & Pentanal \\
\hline 1,1,1-Trichloroethane & 1,2,4-Trimethylbenzene & Hexanal \\
\hline Butanol & D4 & Heptanal \\
\hline Benzene & Decane & Octanol \\
\hline Carbon tetrachloride & Isododecane & Nonanal \\
\hline Cyclohexane & $p$-Dichlorobenzene & Decanal \\
\hline 1,2-Dichloropropane & 2-Ethyl-1-hexanol & \\
\hline Bromodichloromethane & 3-Carene & \\
\hline Trichloroethylene & 1,2,3-Trimethylbenzene & \\
\hline Isooctane & $p$-Cymene & \\
\hline Heptane & Limonene & \\
\hline 4-Methyl-2-pentanone (MIBK) & 4-Ethyl-1,2-dimethylbenzene & \\
\hline Methylcyclohexane & Undecane & \\
\hline Toluene & $1,2,4,5$-Tetramethylbenzene & \\
\hline Dibromochloromethane & D5 & \\
\hline Butyl acetate & Dodecane & \\
\hline Octane & Tridecane & \\
\hline Tetrachloroethylene & D6 & \\
\hline Ethylbenzene & Texanol & \\
\hline m, p-xylene & Tetradecane & \\
\hline Styrene & Pentadecane & \\
\hline o-Xylene & Hexadecane & \\
\hline
\end{tabular}

15 aldehydes analyzed by HPLC 

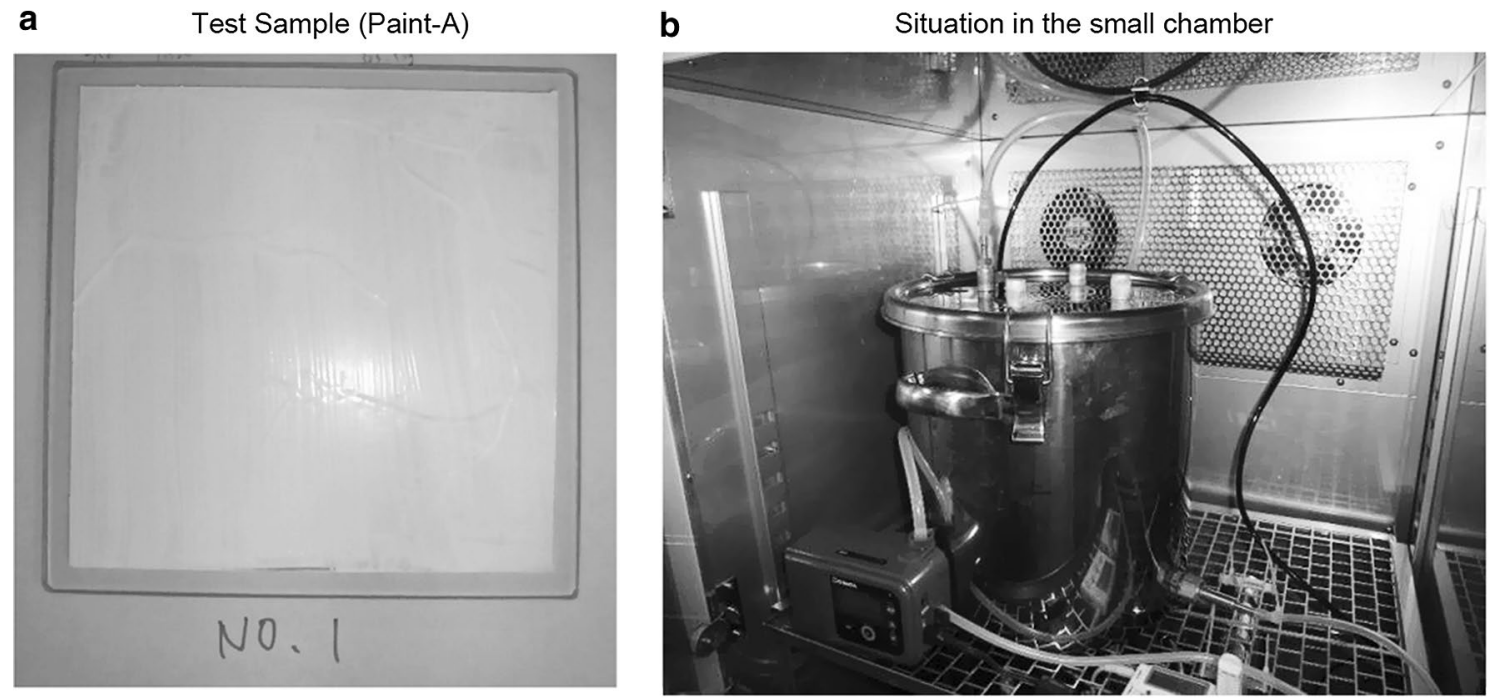

C Situation in the small chamber

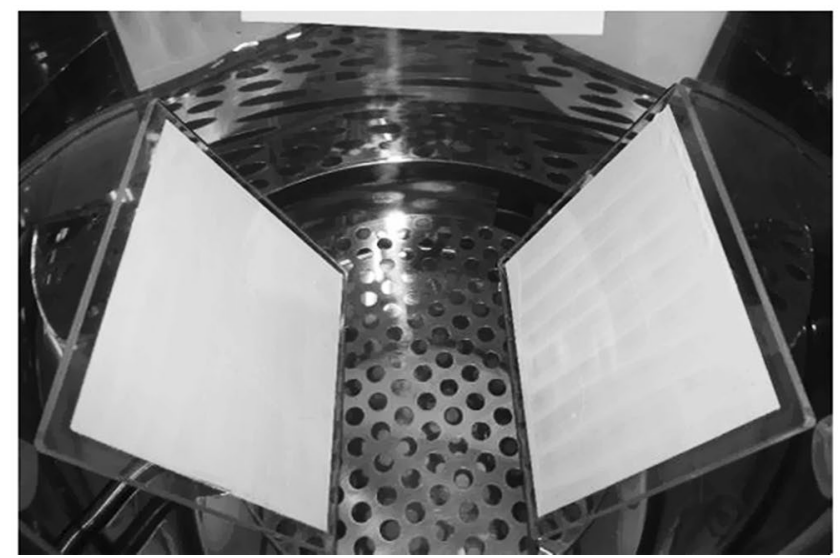

Fig. 1 Small chamber test. a PA test sample; $\mathbf{b}$ situation of the small chamber; $\mathbf{c}$ plate setup in the small chamber

i.d., $3 \mu \mathrm{m})$ made by Sigma-Aldrich. VOCs were measured using a GC6890 and MSD5973N from Agilent. The separation column was the DB-1 $(0.25 \mathrm{~mm}$; i.d $\times 60 \mathrm{~m}, 1.0 \mu \mathrm{m})$ from GL Sciences. For known substances with standards, individual quantities were calculated. For substances that did not have standards, a library search was performed to infer the substance and quantities were calculated by toluene conversion. In this study, the TVOC was calculated as the toluene equivalent of all substances between C6 and C16, as defined by ISO.

\section{Results and discussion}

\section{Results}

Table 4 shows the emission rates of each specimen and the toluene-converted TVOC value.

The emission rates of the guideline value substances stipulated by the MHLW were extremely low. Formaldehyde was $1.0 \mu \mathrm{gm}^{-2} \mathrm{~h}^{-1}$ in the combination sample of PB-SB, but not detected (ND) in other combinations. Compounds for which guideline values were set, such as acetaldehyde, toluene, xylene, ethylbenzene, paradichlorobenzene, and tetradecane, were all classified as ND.

Styrene was detected in all the samples except those of $\mathrm{PB}, \mathrm{PB}+\mathrm{SB}$, and $\mathrm{PC} ; 1.2 \mu \mathrm{gm}^{-2} \mathrm{~h}^{-1}$ styrene in the

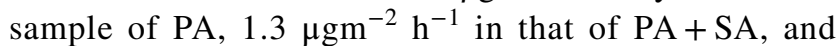


Table 4 Detection levels of selected VOCs and aldehydes analyzed in the test samples

\begin{tabular}{|c|c|c|c|c|c|c|}
\hline Compounds & $\begin{array}{l}\text { PA } \\
\left(\mu \mathrm{gm}^{-2} \mathrm{~h}^{-1}\right)\end{array}$ & $\begin{array}{l}\mathrm{PA}+\mathrm{SA} \\
\left(\mu \mathrm{gm}^{-2} \mathrm{~h}^{-1}\right)\end{array}$ & $\begin{array}{l}\text { PB } \\
\left(\mu \mathrm{gm}^{-2} \mathrm{~h}^{-1}\right)\end{array}$ & $\begin{array}{l}\mathrm{PB}+\mathrm{SB} \\
\left(\mu \mathrm{gm}^{-2} \mathrm{~h}^{-1}\right)\end{array}$ & $\begin{array}{l}\text { PC } \\
\left(\mu \mathrm{gm}^{-2} \mathrm{~h}^{-1}\right)\end{array}$ & $\begin{array}{l}\mathrm{PC}+\mathrm{SC} \\
\left(\mu \mathrm{gm}^{-2} \mathrm{~h}^{-1}\right)\end{array}$ \\
\hline Formaldehyde & ND & ND & ND & 1.0 & ND & ND \\
\hline Acetaldehyde & ND & ND & ND & ND & ND & ND \\
\hline Toluene & ND & ND & ND & ND & ND & ND \\
\hline Xylene & ND & ND & ND & ND & ND & ND \\
\hline Styrene & 1.2 & 1.3 & ND & ND & ND & 1.0 \\
\hline Ethylbenzene & ND & ND & ND & ND & ND & ND \\
\hline$p$-Dichlorobenzene & ND & ND & ND & ND & ND & ND \\
\hline Tetradecane & ND & ND & ND & ND & ND & ND \\
\hline Glycol ethers & ND & ND & ND & ND & 1680 & 1750 \\
\hline Texanol & ND & ND & 27 & 3320 & 555 & 1750 \\
\hline Hexane & 3.2 & 3.2 & ND & 2.0 & 1.1 & 1.3 \\
\hline D4 & 1.7 & 1.0 & ND & ND & ND & ND \\
\hline 2-Ethyl-1-hexanol & 32 & 7.0 & ND & ND & ND & ND \\
\hline D5 & 1.3 & ND & ND & ND & ND & ND \\
\hline Acetone & ND & ND & ND & ND & ND & 1.5 \\
\hline 1-Propanol & ND & ND & ND & ND & ND & 1.0 \\
\hline Total of other substances ${ }^{a}$ & 156 & 84 & 333 & 1427 & 221 & 622 \\
\hline TVOC & 195 & 96 & 360 & 4750 & 2460 & 4130 \\
\hline
\end{tabular}

$N D$ not detected

${ }^{a}$ Value of excluding substances that could be identified from TVOC

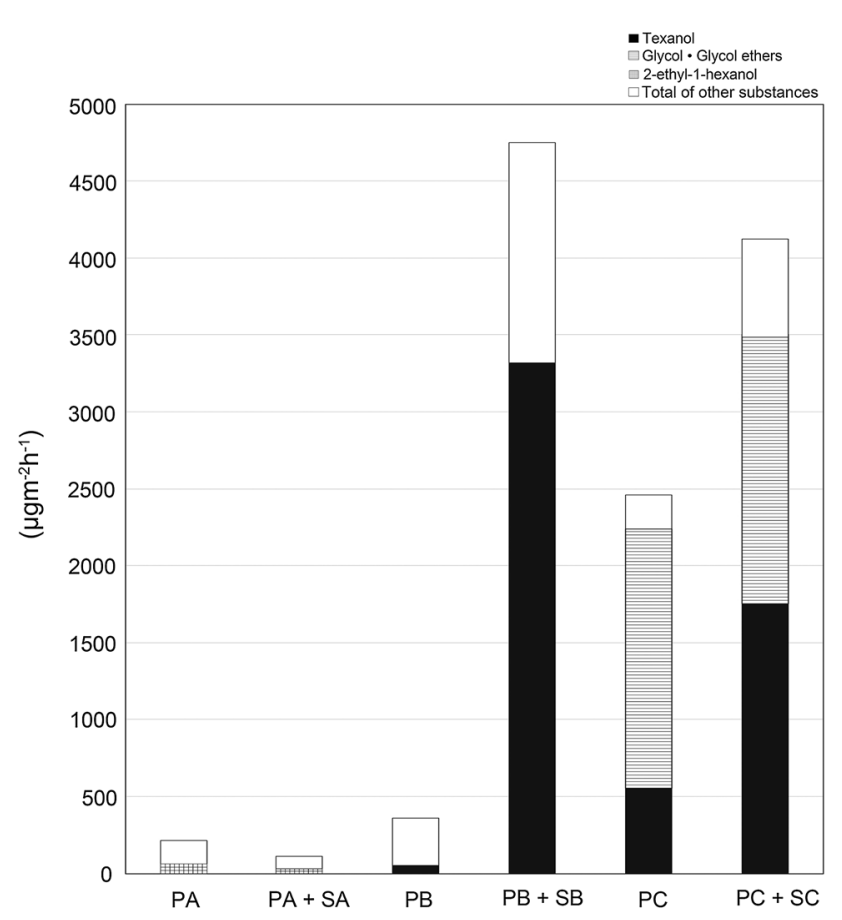

Fig. 2 Emission rates of the highest emitting compounds
$1.0 \mathrm{\mu gm}^{-2} \mathrm{~h}^{-1}$ in that of $\mathrm{PC}+\mathrm{SC}$ were found. Figure 2 and Table 4 show the substances with the highest emission rates, including Texanol ${ }^{\mathrm{TM}}$, glycol ether, and 2-ethyl1-hexanol. The substance detected most abundant was Texanol $^{\mathrm{TM}}$, which was detected in all combinations except for PA and PA + SA. Texanol ${ }^{\mathrm{TM}}$ was detected at $27 \mu \mathrm{gm}^{-2} \mathrm{~h}^{-1}$ in $\mathrm{PB}$; $3320 \mu \mathrm{gm}^{-2} \mathrm{~h}^{-1}$ in $\mathrm{PB}+\mathrm{SB}$; $555 \mu \mathrm{gm}^{-2} \mathrm{~h}^{-1}$ in $\mathrm{PC}$; and $1750 \mu \mathrm{gm}^{-2} \mathrm{~h}^{-1}$ in $\mathrm{PC}+\mathrm{SC}$. The next most abundant substance detected was glycol ether at $1680 \mu \mathrm{gm}^{-2} \mathrm{~h}^{-1}$ in $\mathrm{PC}$ and $1750 \mu \mathrm{gm}^{-2} \mathrm{~h}^{-1}$ in $\mathrm{PC}+\mathrm{SC}$. In PA, PA + SA, $\mathrm{PB}$, and $\mathrm{PB}+\mathrm{SB}$, glycol ether was ND. 2-Ethyl-1-hexanol was detected at $32 \mu \mathrm{gm}^{-2} \mathrm{~h}^{-1}$ in PA and $7.0 \mu \mathrm{gm}^{-2} \mathrm{~h}^{-1}$ in $\mathrm{PA}+\mathrm{SA}$. The toluene-converted TVOC was $195 \mu \mathrm{gm}^{-2} \mathrm{~h}^{-1}$ in PA; $96 \mu \mathrm{gm}^{-2} \mathrm{~h}^{-1}$ in $\mathrm{PA}+\mathrm{SA} ; 360 \mu \mathrm{gm}^{-2} \mathrm{~h}^{-1}$ in $\mathrm{PB}$; $4750 \mu \mathrm{gm}^{-2} \mathrm{~h}^{-1}$ in $\mathrm{PB}+\mathrm{SB} ; 2460 \mu \mathrm{gm}^{-2} \mathrm{~h}^{-1}$ in $\mathrm{PC}$; and $4130 \mu \mathrm{gm}^{-2} \mathrm{~h}^{-1}$ in $\mathrm{PC}+\mathrm{SC}$, revealing remarkable differences in the emission rates among $\mathrm{W} 1$ class paints.

\section{Discussion}

To the best of our knowledge, this is the first study to compare Japanese low-VOC and W1 classified paints (VOC content lower than 1\%) and sealers. In this study, VOC contents 
and emission raters of three types of low-VOC paints with and without sealers were investigated. Conventionally, sealers are used in combination with paints, and it is recommended to use products produced by the same manufacturer. Therefore, in addition to the performance of the paint, it is also necessary to consider the performance of their combination with the sealers. The results of our experiments revealed that there were big differences in VOCs emitted among low-VOC and W1 classification paints and various combinations of paints and sealers. They also indicate that emission rates of eight substances which are set guideline values by MHLW were low in every sample, but in some samples, other substances such as Texanol ${ }^{\mathrm{TM}}$, glycol ether, 2-ethyl-1-hexanol, and TVOC were detected high. The result for samples of PA, PA + SA, and PB shows extremely few substances detected and low emission rates. For samples of PA and PA + SA, Texanol ${ }^{\mathrm{TM}}$ was ND and the VOC emission rates were much lower than those of the other combinations. Conversely, in samples of $\mathrm{PB}+\mathrm{SB}, \mathrm{PC}$, and $\mathrm{PC}+\mathrm{SC}$, $\mathrm{Texanol}^{\mathrm{TM}}$ was detected at high concentrations, showing that VOC emission rates were higher than those of the other non-Texanol ${ }^{\mathrm{TM}}$-containing combinations. Comparing Texanol $^{\mathrm{TM}}$ in paint only and paint + sealer, the detected emission was $27 \mu \mathrm{gm}^{-2} \mathrm{~h}^{-1}$ in $\mathrm{PB} ; 3320 \mu \mathrm{gm}^{-2} \mathrm{~h}^{-1}$ in $\mathrm{PB}+\mathrm{SB}$;

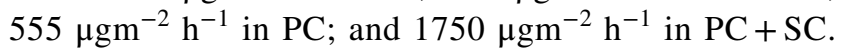
Based on these findings, the major source of Texanol ${ }^{\mathrm{TM}}$ was assumed to be sealers. Kobayashi et al. (2010) conducted the research on the SBS incidence that occurred in a newly constructed elementary school in Hokkaido, Japan in 2007, and they reported that the causative substances were suspected to be 1-methyl-2-pyrrolidone and Texanol ${ }^{\mathrm{TM}}$ emitted from water-based paints. The concentration of Texanol ${ }^{\mathrm{TM}}$ in indoor air should therefore be reduced, and attention must be paid to the use of sealers. In the samples of PC and PC + SC case, along with Texanol ${ }^{\mathrm{TM}}$, glycol ether was also detected, and TVOC emission rates were high. The source of glycol ether was suspected to be paint C. Focusing only on paints, the concentration of TVOC was lower in the sample of PB than in that of PC. However, the results of combining paints with sealers indicated the TVOC concentration in the sample of $\mathrm{PB}+\mathrm{SB}$ was higher than in that of $\mathrm{PC}+\mathrm{SC}$. The result depends on the concentration of Texanol ${ }^{\mathrm{TM}}$ in the sample of SB; i.e., TVOC concentration varies depending on the combination of paints and sealers. According to previous studies (WHO 1989; EC 1997; German Committee 2018), it was reported that the occurrence of SBS symptoms is more likely with increasing TVOC values in indoor air; therefore, it is recommended not to exceed $300-400 \mu \mathrm{g} \mathrm{m}^{-3}$ (Nakaoka et al.
2014). Emission rates of substances shown in Table 4 were the results of 7 days after application. It means that TVOC levels in indoor air should be reduced by intense ventilation and so on during or 7 days more after the use of some types of combination of paints and sealers.

The emission rates of styrene and 2-ethyl-1-hexanol from samples were low, and they are not regulated by the Japanese government; however, they could act as substitutes for regulated substances and have some influence on people. In recent years, reports establishing the relation between adverse health effects and styrene and 2-ethyl-1-hexanol have appeared (Loomis et al. 2018; Kamijima et al. 2002; Wieslander et al. 2010; Sakai et al. 2006). The total concentration of other substances (value of excluding substances that could be identified from TVOC) was $156 \mu \mathrm{gm}^{-2} \mathrm{~h}^{-1}$ in PA, $84 \mu \mathrm{gm}^{-2} \mathrm{~h}^{-1}$ in the samples of PA $+\mathrm{SA}, 333 \mu \mathrm{gm}^{-2} \mathrm{~h}^{-1}$ in $\mathrm{PB}, 1427 \mu \mathrm{gm}^{-2} \mathrm{~h}^{-1}$ in $\mathrm{PB}+\mathrm{SB}, 221 \mu \mathrm{gm}^{-2} \mathrm{~h}^{-1}$ in $\mathrm{PC}$, and $622 \mu \mathrm{gm}^{-2} \mathrm{~h}^{-1}$ in $\mathrm{PC}+\mathrm{SC}$. These results show that although their individual peaks are low, if they are totaled, there are cases wherein the "the totals of other substances" can account for much of the emitted VOC content. We therefore also should pay attention to the chemicals that are excluded from TVOC. Schieweck and Bock (2015) concluded from their study that a quality label of low-VOC paints just meant that a specific product fulfilled specific requirements, and it does not state that a specific product is free of chemicals or emissions. To prevent adverse health effects from chemicals in indoor air, it will be necessary to conduct studies on substances even if they are excluded from regulation targets, and the products were labeled low or free VOCs.

\section{Conclusion}

VOC contents and emission rates of $\mathrm{W} 1$ class, low-VOC, water-based, and emulsion paints with and without sealers were examined in this study. Great differences in VOC emission rates among them were recognized. Paints with VOC contents lower than $0.2 \%$ and $0.3 \%$ (PA and $\mathrm{PB}$ ) showed $\mathrm{VOC}$ emission rates that were far lower than those of paints with $1 \%$ or less VOC content (PC). The main constituents of these TVOC were Texanol ${ }^{\mathrm{TM}}$ and glycol ether. As seen in samples of $\mathrm{PB}, \mathrm{PB}+\mathrm{SB}, \mathrm{PC}$, and $\mathrm{PC}+\mathrm{SC}$, the selection of paints and sealers greatly affects the VOC emission rates. Recently, many paints and sealers have been made 
commercially available; however, there is not enough information for consumers regarding product emission testing. It is required finer VOC classification system in paints and sealers to assist consumers in choosing healthier environments. For the purpose of reducing SBS and protect public health, it is important to devote more effort for investigating paints and sealers.

Acknowledgements This work was supported by JSPS (Japan Society for the Promotion of Science) Grants-in-Aid for Scientific Research (C) Grant Number JP15K00613.

\section{Compliance with ethical standards}

Conflict of interest The authors declare that they have no conflicts of interest.

Open Access This article is distributed under the terms of the Creative Commons Attribution 4.0 International License (http://creativeco mmons.org/licenses/by/4.0/), which permits unrestricted use, distribution, and reproduction in any medium, provided you give appropriate credit to the original author(s) and the source, provide a link to the Creative Commons license, and indicate if changes were made.

\section{References}

Alevantis LE (1996) Reducing occupant exposure to volatile organic compounds (VOCs) from office building construction materials: non-binding guidelines. California Department of Health Services Report released July

Azuma K, Uchiyama I, Uchiyama S, Kunugita N (2016) Assessment of inhalation exposure to indoor air pollutants: screening for health risks of multiple pollutants in Japanese dwellings. Environ Res 145:39-49

Boxall J, Carey JK, Miller ER (1992) The effectiveness of end-grain sealers in improving paint performance on softwood joinery. Eur J Wood Wood Prod 50(6):227-232

Brinke JT, Selvin S, Hodgson AT, Fisk WJ, Mendell MJ, Koshland CP, Daisey JM (1998) Development of new VOC exposure metrics and their relationship to "sick building syndrome" symptoms. Indoor Air 8:140-152

Deng B, Kim CN (2004) An analytical model for VOCs emission from dry building materials. Atmos Environ 38:1173-1180

European Commission (EC) (1997) Total volatile organic compounds (TVOC) in indoor air quality investigations. Indoor air quality and its impact on man. Report no 19, Luxembourg
Fang L, Clausen G, Fanger PO (1999) Impact of temperature and humidity on chemical and sensory emissions from building materials. Indoor Air 9:193-201

German Committee on Indoor Guide Values (2018). https://www. umweltbundesamt.de/en/topics/health/commissions-workinggroups/german-committee-on-indoor-guide-values\#textpart-1

Heinrich J (2011) Influence of indoor factors in dwellings on the development of childhood asthma. Int J Hyg Environ Health 214:1-25

Herberth G, Gubelt R, Roeder S, Kraemer U, Schins R, Diez U, Borte M, Heinrich J, Wichmann H, Herbarth O, Lehmann I (2009) Increase of inflammatory markers after indoor renovation activities: the LISA birth cohort study. Pediatr Allergy Immunol 20:563-570

Hodgson M (2002) Indoor environmental exposures and symptoms. Environ Health Perspect 110(Suppl 4):663

http://www.kokusen.go.jp/news/data/a_W_NEWS_101.html. Website of The National Consumer Affairs Center of Japan (in Japanese), 21 Apr 1998

Japanese Ministry of Environment (2007) Guide to VOC reduction. https://www.env.go.jp/air/osen/voc/pamph4/full.pdf. Accessed 28 Oct 2018

JSA. JIS A 1901 (2009) Determination of the emissions of VOCs and aldehydes for building products—-small chamber method. Japan Standards Association, Tokyo

Kamijima M, Sakai K, Shibata E, Yamada T, Itohara S, Ohno H, Hayakawa R, Sugiura M, Yamaki K, Takeuchi Y (2002) 2-Ethyl1-hexanol in indoor air as a possible cause of sick building symptoms. J Occup Health 44:186-191

Kim SS, Kang DH, Choi DH, Yeo MS, Kim KW (2012) VOC emission from building materials in residential buildings with radiant floor heating systems. Aerosol Air Qual Res 12:1398-1408

Kobayashi S, Takeuchi S, Kojima H, Takahashi T, Jin K, Akitsu H, Isaji $S$ (2010) Indoor air pollution in a newly constructed elementary school caused by 1-methyl-2-pyrrolidone and Texanol emitted from water-based paints. Indoor Environ 13:39-54

Loomis D, Guha N, Kogevinas M, Fontana V, Gennaro V, Kolstad H, Mcelvenny DM, Sallmen M, Saracci R (2018) Cancer mortality in an international cohort of reinforced plastics workers exposed to styrene: a reanalysis. Occup Environ Med. https://doi.org/10.1136/ oemed-2018-105131

Molhave L (2003) Organic compounds as indicators of air pollution. Indoor Air 13:12-19

Mori C, Todaka E (2011) Environmental contaminants and children's health. Maruzen Planet Co., Ltd., pp 99-115. http://cpms.chiba -u.jp/. Accessed 28 Oct 2018

Nakaoka H, Todaka E, Seto H, Saito E, Hanazato M, Watanabe M, Mori C (2014) Correlating the symptoms of sick building syndrome to indoor VOCs concentration levels and odour. Indoor Built Environ 23(6):804-813

Norbäck D, Michel I, Widström J (1990a) Indoor air quality and personal factors related to the sick building syndrome. Scand J Work Environ Health 16(2):121-128

Norbäck D, Torgen M, Edling C (1990b) VOCs, respirable dust, and personal factors related to prevalence and incidence of sick 
building syndrome in primary schools. Occup Environ Med 47:733-741

Nordström K, Norbäck D, Akselsson R (1995) Influence of indoor air quality and personal factors on the sick building syndrome (SBS) in Swedish geriatric hospitals. Occup Environ Med 52:170-176

Park DW, Kim SH, Moon JY, Song JS, Choi J, Kwak HJ, Jeong MG, Ro YS, Kim TH, Sohn JW, Shin DH, Park SS, Yoon HJ (2017) The effect of low-VOCs, water-based paint on aggravation of allergic disease in school children. Indoor Air 27:320-328

Sakai K, Kamijima M, Shibata E, Ohno H, Nakajima T (2006) Indoor air pollution by 2-ethyl-1-hexanol in non-domestic buildings in Nagoya, Japan. J Environ Monit 8:1122-1128

Schieweck A, Bock MC (2015) Emissions from low-VOC and zeroVOC paints-valuable alternatives to conventional formulations also for use in sensitive environments? Build Environ 85:243-252
Schneider T, Sundell J, Bischof W, Bohgard M, Cherrie JW, Clausen PA, Dreborg S, Kildes $\emptyset$ J, Kjærgaard SK, Løvik M, Pasanen P (2003) 'EUROPART'Airborne particles in the indoor environment. A European interdisciplinary review of scientific evidence on associations between exposure to particles in buildings and health effects. Indoor Air 13:38-48

Wieslander G, Anders K, Dan N (2010) Dampness and 2-ethyl-1-hexanol in floor construction of rehabilitation center: health effects in staff. Arch Environ Occup Health 65:3-11

World Health Organisation (WHO) (1989) Indoor air quality: organic pollutants, EURO reports and studies no. 111, Copenhagen

Zhang Y, Ying X (2003) Characteristics and correlations of VOC emissions from building materials. Int $\mathrm{J}$ Heat Mass Transf 46:4877-4883 